\title{
Minimization of Phenol by Natural Occurrence Adsorbent
}

\author{
Jigar Joshi, Omprakash Sahu* \\ Department of Chemical Engineering, KIT Jamnagar (Gujarat), India \\ *Tel: +919752610957 \\ E-mail address: ops0121@gmail.com
}

\begin{abstract}
Phenol and chlorophenols are long-lived pollutants frequently found in industrial effluents. Phenols are widely used for the commercial production of a wide variety of resins including phenolic resins, epoxy resins and adhesives, and polyamide for various applications. Adsorption process has been proven one of the best water treatment technologies around the world and the removal of diverse types of pollutants from water. However, widespread use of commercial adsorbent is sometimes restricted due to its higher costs. Attempts have been made to develop inexpensive adsorbents utilizing for the reduction of phenol from water. Four types of adsorbent clay, algae, moringa oleifera and rice husk has been used. Among all rice husk shown $97 \%$ of phenol adsorption at $1 \mathrm{~mm}$ particle size, $\mathrm{pH}$ 4, $3 \mathrm{~g} / \mathrm{l}$ dosing and 150min contact time.
\end{abstract}

Keywords: Algae; Bioadsorption; Clay; Effluent; Ions

\section{INTRODUCTION}

Environmental pollution is an emerging threat and of great concern in today's context pertaining to its effect on the ecosystem. Water pollution is one of the greatest concerns now a day. In recent years, considerable attention has been paid to industrial wastes discharged to land and surface water [1]. Industrial effluents often contain various toxic metals, harmful dissolved gases, and several organic and inorganic compounds. These may accumulate in soil in excessive quantities in long-term use, ultimately physiologically adverse effects on crop productivity [2]. The worldwide rise in population and the industrialization during the last few decades have resulted in ecological unbalance and degradation of the natural resources [3]. One of the most essential natural resources, which have been the worst victim of population explosion and growing industrialization, is water. Huge quantity of wastewater generated from human settlement and industrial Sectors accompany the disposal system either as municipal wastewater or industrial wastewater [3]. This wastewater is enriched with varied pollutants and harmful both for human being and the aquatic flora and fauna, finds it way out into the nearly flowing or stationary water bodies and thus makes natural sources of water seriously contaminated [5]. It has been estimated that over 5 million chemical substances produced by industries have been identified and about 12000 of these are marketed which amount to around half of the total production. Due to discharge of toxic effluents long-term consequence of exposure can cause cancer, delayed nervous damage, 
malformation in urban children, mutagenic changes, neurological disorders etc. [6]. Various acid manufacturing industries discharge acidic effluent, which not only make the land infertile. But make the water of the river acidic also. The high acidity causes stomach diseases and skin ailments in human beings [7].

Thus it is imperative to purify and recycle wastewater in view of reduced availability and deteriorating water quality. Phenol along with other xenobiotic compounds is one of the most common contaminants present in effluents from chemical process industries. Even at lower concentration these compounds adversely affect aquatic as well as human life $[8,9]$. Also these compounds form complexes with metal ions discharged from other industries, which are carcinogenic in nature. It is water soluble and highly mobile. This imparts medicinal taste and odour even at much lower concentration of $2 \mu \mathrm{g} / \mathrm{l}$ and it is lethal to fish at concentrations of $5-25 \mathrm{mg} / 1$ [10]. The maximum permitted concentration level of phenol being $0.5-1 \mathrm{mg} / 1$ for industrial wastewater and $1 \mu \mathrm{g} / 1$ for drinking water $[11,12]$. So it is highly essential to save the water resources and aquatic life by removing these compounds from wastewater before disposal.

The main sources of phenolic wastewater are coal chemical plants, oil refineries, petrochemical industries, fibre glass units, explosive manufacture, phenol-based polymerization process, pharmaceuticals, plastic, paints and varnish producing units, textile units making use of organic dyes, anticeptics, antirust products, biocides, photographic chemicals and smelting and related metallurgical operations, etc. $[13,14]$. The conventional methods of treatment of phenolic and nitrate-nitrogen wastewater are largely physical and chemical processes but these processes led to secondary effluent problems due to formation of toxic materials such as cyanates, chlorinated phenols, hydrocarbons, etc. These methods are mainly chlorination, ozonation, solvent extraction, incineration, chemical oxidation, membrane process, coagulation, flocculation, adsorption, ion exchange, reverse osmosis, electrolysis, etc. [9-14]. The goal of study is minimized the phenol contain wastewater by low cost treatment. Natural occurrence materials are used as adsorbent for reduction. The effect of $\mathrm{pH}$, dosing, contact time, isotherm has been also studied [25-32].

\section{MATERIAL AND METHODS}

\section{1. Material}

\subsection{Adsorbent}

The adsorbent clay $(\mathrm{C})$, rice husk $(\mathrm{RH})$, algae $(\mathrm{A})$ and Moraga oleifera $(\mathrm{MO})$ was arranged from local region. All the adsorbent were washed with generous amounts of distilled water and dried in an oven at $60^{\circ} \mathrm{C}$ overnight. Then, they were sieved in the size pore range from 0.25 to $1.5 \mathrm{~mm}$.

\section{1. 2. Phenol water}

The synethic water was made in labotary; The phenolic compounds used in this study were phenol, 2-chlorophenol (2-CP) and 4-chlorophenol (4-CP). A stock solution was prepared by dissolving $1.0 \mathrm{~g}$ of phenol, $2-\mathrm{CP}$ or $4-\mathrm{CP}$ in $1 \mathrm{dm} 3$ of deionised water. The phenolic solutions for the sorption experiments were prepared by diluting the stock solution to give different concentrations within the range 10 to $500 \mathrm{mg} \mathrm{dm}^{-3}$ for phenol and 10 to 1000 $\mathrm{mg} \mathrm{dm}{ }^{-3}$ for chlorophenols [15]. 


\section{2. Methods}

The batch experiments were conducted by mixing $100 \mathrm{~mL}$ of synethic water prepared in the labotary. The adsorbent collected from the local region was putting for $2 \mathrm{hr}$ in $100 \mathrm{~mL}$ glass bottles at room temperature. After $2 \mathrm{hr}$ mixing, the mixtures were centrifuged at 4000 rpm for 10 minutes and decanted before final analysis. Adsorption studies were carried out by batch process. A measure amount $(50 \mathrm{ml})$ of wastewater solution with measure amount of salts (or pollutant minerals) at concentration $C_{I}$ was mixed with a one gram of dried and grinded absorbent without any pre-treatment. The solutions put in contact with the adsorbents were maintained at a constant temperature of $25{ }^{\circ} \mathrm{C}$ in a water bath thermostat, the mixture being vigorously stirred by means of a magnetic stirrer. The sampled solutions were centrifuged at $5000 \mathrm{rpm}$ for $15 \mathrm{~min}$ with a centrifugation machine. The variation of the adsorbed ions concentration $\left(\mathrm{C}_{\mathrm{r}}\right)$ represented in the figures is defined as $\mathrm{C}_{\mathrm{r}}=\mathrm{C}_{0}-\mathrm{C}_{\mathrm{f}}$ for the ratio $25 \mathrm{~g} / 1$ of mass/solution, and the removal percentage of pollutant from wastewater $(\mathrm{E})$ on micro-particles of clay, was calculated from equation mention below.

$$
E(\%)=\frac{\mathrm{C}_{0}-\mathrm{C}_{\mathrm{f}}}{\mathrm{C}_{0}} \times 100
$$

where $\mathrm{C}_{0}$ and $\mathrm{C}_{\mathrm{f}}$ are the initial and equilibrium concentration of pollutant solution $(\mathrm{mg} / \mathrm{l})$, respectively. The capacity $(\mathrm{mg} / \mathrm{g})$ of pollutants adsorbed from wastewaters by micro-particles of clay was calculated from

$$
q_{a}=\frac{\mathrm{C}_{0}-\mathrm{C}_{\mathrm{f}}}{\mathrm{m}} \times v
$$

where, $\mathrm{V}$ is the total solution volume $(\mathrm{ml}), \mathrm{m}$ the weight of the materials $(\mathrm{g})$.

\section{RESULT AND DISCUSSION}

\section{1. Effect of particle size}

The effect of particle size was carried out at $2 \mathrm{~g} / \mathrm{l}$ dosing, $90 \mathrm{~min}$ experimental time, $\mathrm{pH}$ 8 with $0.25 \mathrm{~mm}$ to $1.50 \mathrm{~mm}$ particle size. The result represent in Fig. 1. From the results it was found that percentage reduction of phenol was increase with increase with the particle size, after that it became constant. The maximum phenol reduction $77 \%$ moringa oleifera (MO), $74 \%$ algae (A), $72 \%$ rice husk $(\mathrm{RH})$ and $69 \%$ clay (C) at $1 \mathrm{~mm}$ particle sized respectively. The particle size play important role for adsorption due to it provides more surface area for adsorbs. At the surface of the solids, there are unbalanced forces of attraction which are responsible for adsorption. In cases where the adsorption is due to weak van der Waals forces, it is called physical adsorption. On the other hand, there may be a chemical bonding between adsorbent and adsorbate molecule and such type of adsorption is referred as chemisorption [16]. 


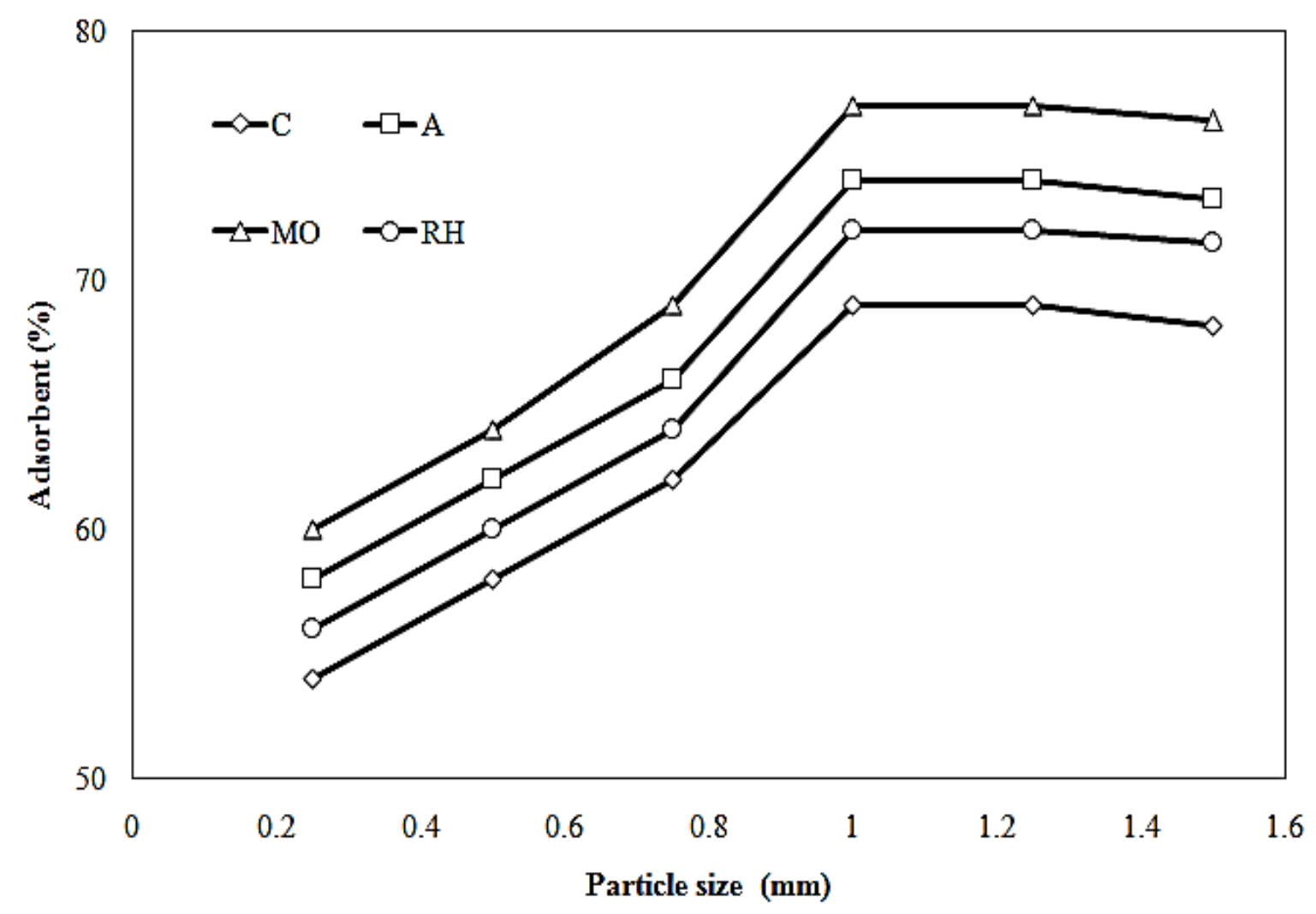

Fig. 1. Effect of particles size on adsorption of phenol.

\section{2. Effect of $\mathbf{p H}$}

The effect of $\mathrm{pH}$ was carried out at $2 \mathrm{~g} / \mathrm{l}$ dosing, $1 \mathrm{~mm}$ particles size, $90 \mathrm{~min}$ experimental time with different $\mathrm{pH}$ (2 to 12$)$. The $\mathrm{pH}$ was adjusted by $0.1 \mathrm{M}$ of HCL and 0.1 $\mathrm{NaOH}$ solutions, which is shown in Fig. 2. The result shows that maximum $85 \%$ phenol adsorption occurred with rice husk $(\mathrm{RH})$ at $\mathrm{pH} 4$. The adsorbent of moringa oleifera shows 83 $\%$, at $\mathrm{pH} 6$, clay $80 \%$ at $\mathrm{pH} 4$ and algae $78 \%$ at $\mathrm{pH} 6$. The $\mathrm{pH}$ of the solution play an important role in the whole adsorption process and particularly on the adsorption capacity, influencing not only the surface charge of the adsorbent, the degree of ionization of the material present in the solution and the dissociation of functional groups on the active sites of the adsorbent. The hydrogen and hydroxyl ions are adsorbed quite strongly, and therefore, the adsorption of other ions is affected by the $\mathrm{pH}$ of the solution. It is a commonly known fact that the anions are favorably adsorbed by the adsorbent at lower $\mathrm{pH}$ values due to presence of $\mathrm{H}+$ ions and at high $\mathrm{pH}$ values, cations are adsorbed due to the negatively charged surface sites [17]. Mahvi et al. investigated the potential of rice husk and rice husk ash for phenol removal from aqueous solution [18].

It was observed by them that rice husk ash was more effective than rice husk for phenol removal and can be used as an efficient adsorbent for the removal of phenolic compounds from wastewater. Chemically and thermally treated rice husk (RHT) was used as an adsorbent for the removal of 2,4-dichlorophenol from aqueous solution by Akhtar et al. [19]. 


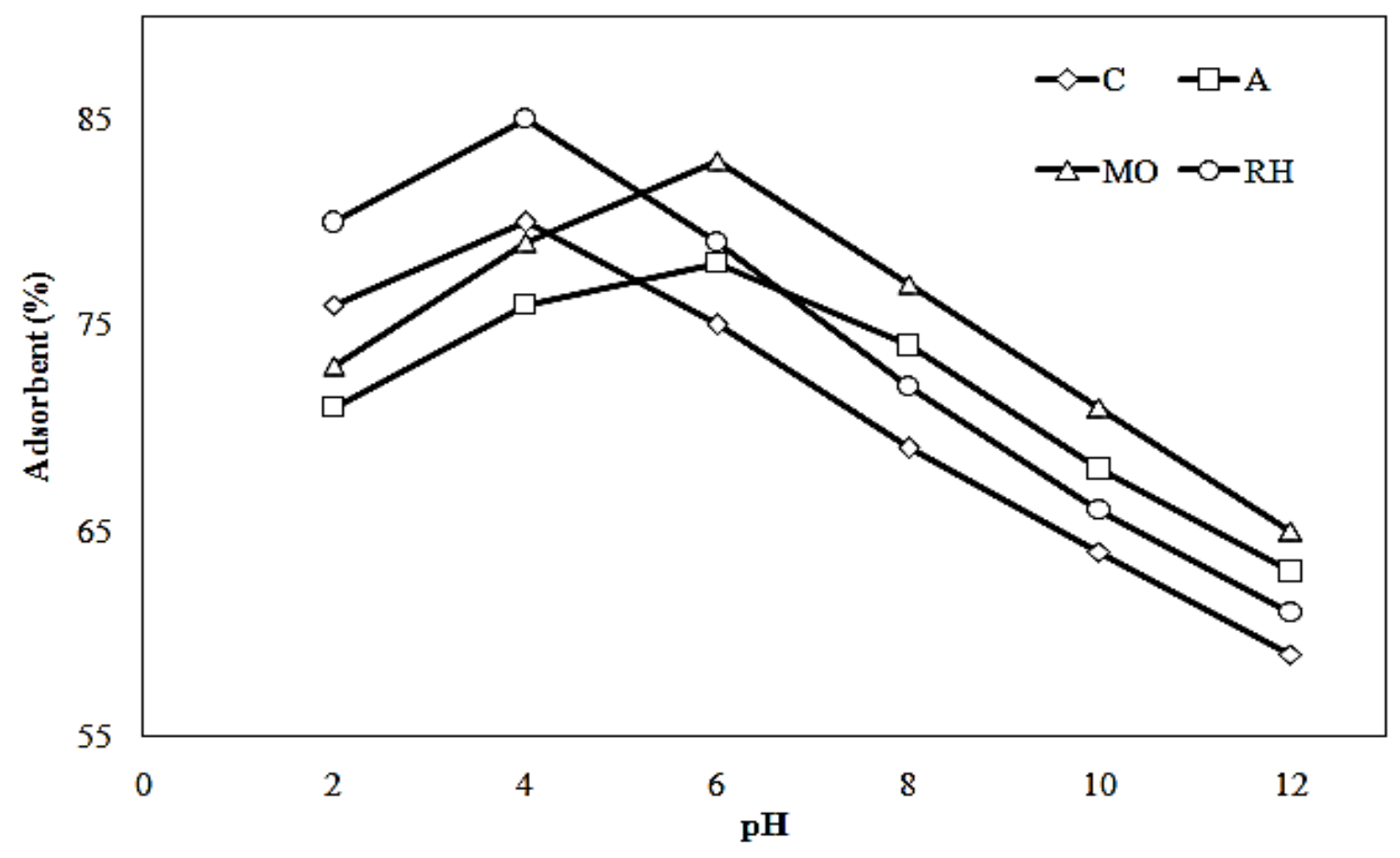

Fig. 2. Effect of $\mathrm{pH}$ on adsorption of phenol.

\section{3. Effect of dosing}

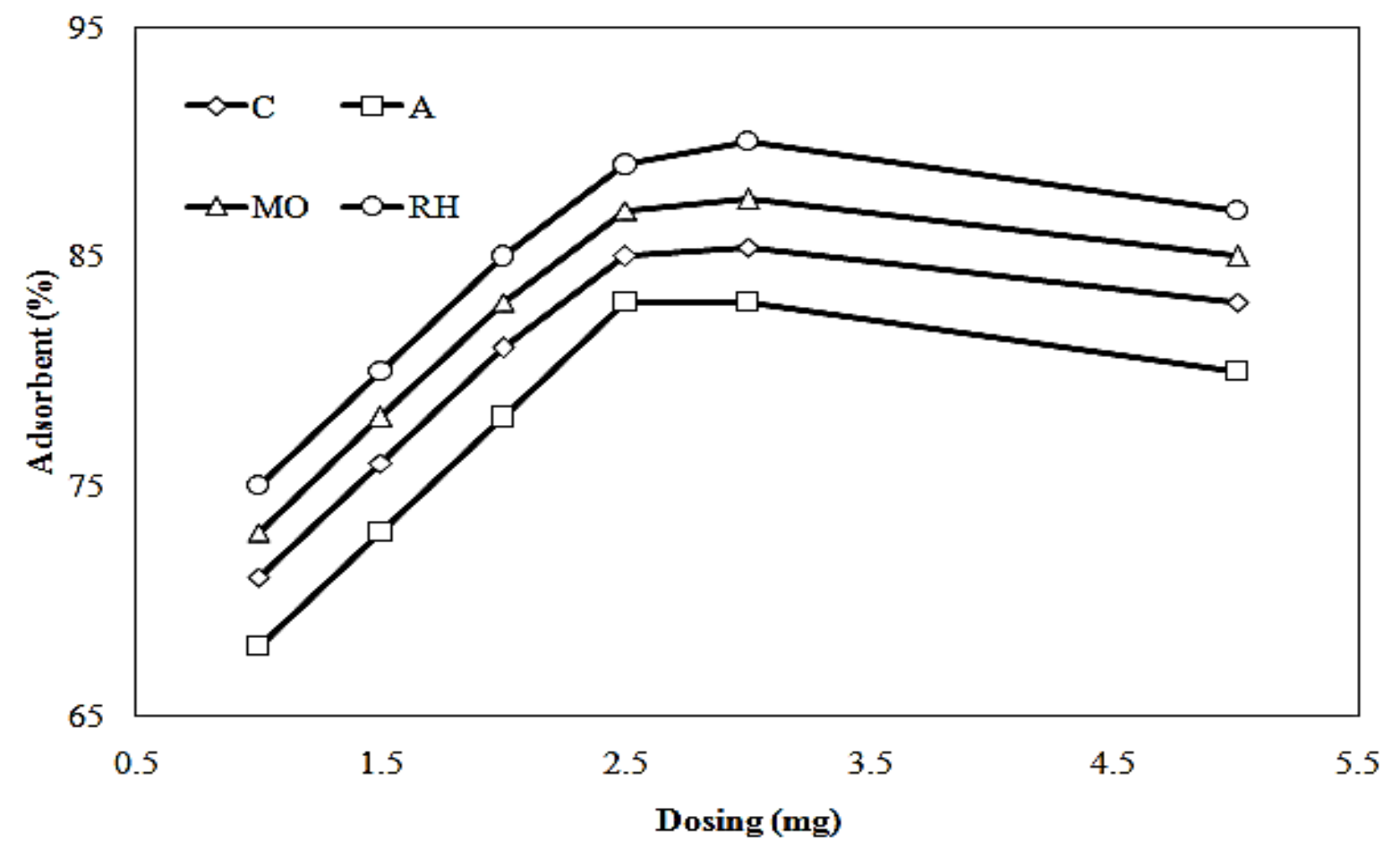

Fig. 3. Effect of dosing on phenol adsorption. 
The effect of dosing was carried out at optimum $\mathrm{pH}$ (clay and rice husk $\mathrm{pH}$ and (algae

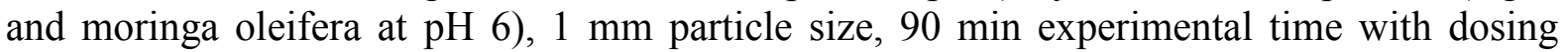
from $1 \mathrm{~g} / \mathrm{l}$ to $5 \mathrm{~g} / \mathrm{l}$. The result represent in Fig. 3. From the result it was found that maximum $90 \%$ adsorption shown by rice husk at $3 \mathrm{~g} / \mathrm{l}$ dosing. At the same dosing of clay shows $85.4 \%$ adsorption, moringa oleifera and algae $87 \%$ and $83 \%$ adsorption at $2.5 \mathrm{~g} / 1 \mathrm{dosing}$.

The adsorption increase with increase in dose may be due to due to the greater surface area with more functional groups consequent to the increase in the number of particles with more number of exchangeable sites for adsorption and saturation occurs as a result of non availability of exchangeable sites on the adsorbent.

The maximum sorption $(98 \pm 1.2 \%)$ was achieved for RHT from $6.1 \times 10^{-5} \mathrm{~mol} / \mathrm{dm}^{3}$ of sorbate solution using $0.1 \mathrm{~g}$ of rice husk for $10 \mathrm{~min}$ agitation time at $\mathrm{pH} 6$ and $303 \mathrm{~K}$, which was comparable to commercial activated carbon $(96.6 \pm 1.2 \%)$, but significantly higher than chemically treated rice husk $(65 \pm 1.6 \%)$ and untreated rice husk $(41 \pm 2.3 \%)$. Several other researchers also studied the application of rice husk as adsorbent for the removal of different pollutants from water [20,21].

\section{4. Effect of contact time}

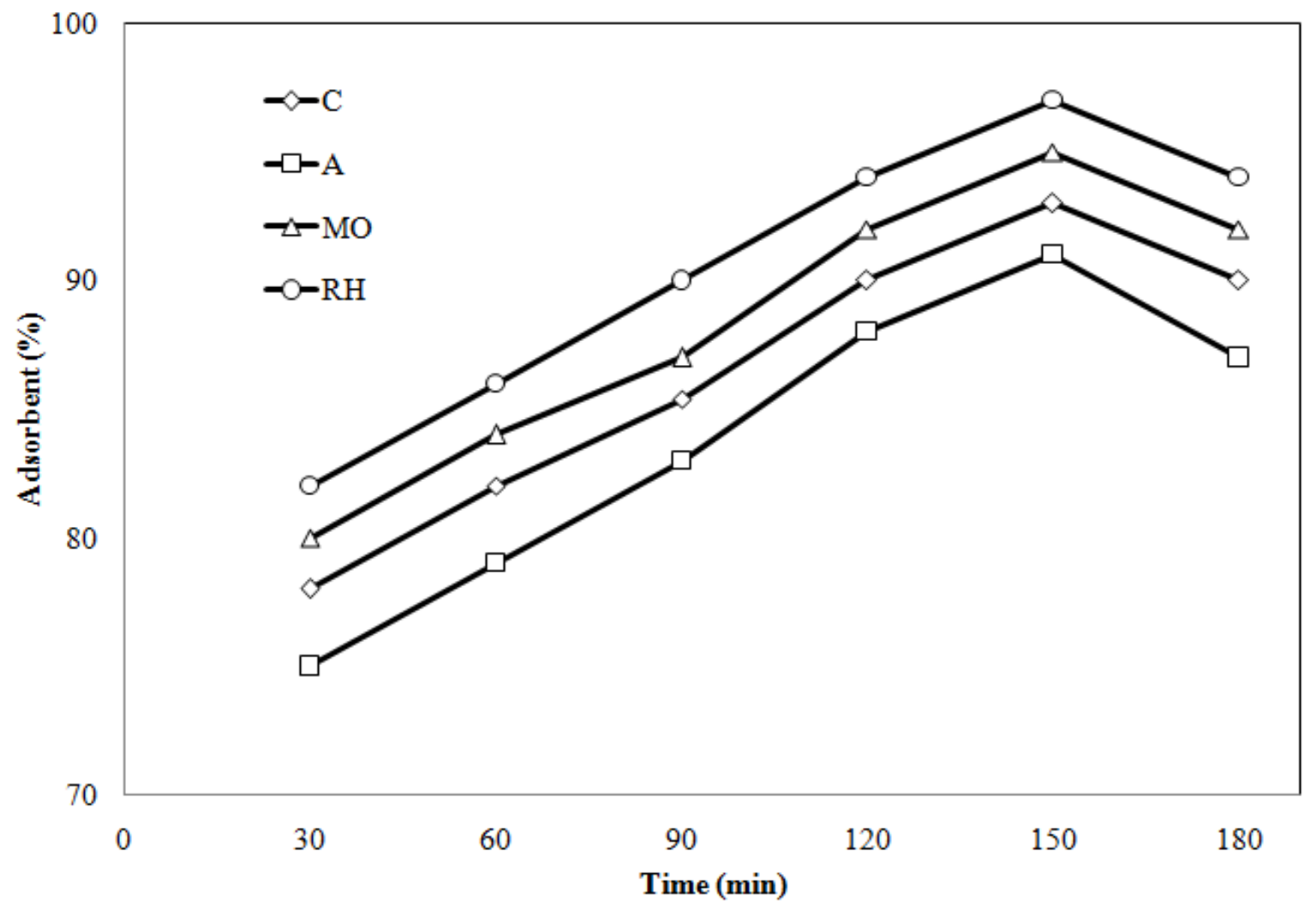

Fig. 4. Effect of contact time on phenol adsorption.

The effect of contact time was carried out optimum $\mathrm{pH}$, optimum dosing, and $1 \mathrm{~mm}$ particle size with experimental time variation from $30 \mathrm{~min}$ to $180 \mathrm{~min}$. The result represented in Fig. 4. From the result it was found that maximum $97 \%$ adsorption shown by rice husk at 
$150 \mathrm{~min}$ of experimental time. Almost all adsorbate show good efficiency at $150 \mathrm{~min}$ of contact time, moringa oleifera $95 \%$, clay $93 \%$ and algae $91 \%$ respectively.

The adsorption increase with increase with time may due to that time is sufficient to reach equilibrium. After reaching maximum adsorptions it was decrease may this is because the agitation of the solution facilitates the rate of transport of the adsorbate species from the outer sites to the interior site of the adsorbent. As the vacant sites are occupied the rate of adsorption becomes decrease [22].

\section{5. Isotherm Study}

Adsorption isotherm helps in determining the properties of the adsorbents such as pore volume pore size or energy distribution and specific surface area. The isotherm curve can also be utilized to obtain information concerning the desorption mechanism strictly connected with interaction between the adsorbent and adsorbate molecules. Therefore, the efficiency of an industrial adsorbent can be accessed through this curve.

The correct interpretation of experimental adsorption isotherm can be realized in terms of some mathematical equations called adsorption isotherm model equations [23]. Such equations are derived assuming an ideal physical model for the adsorption system. The model assumptions are usually a result of experimental observations. For this study Langmuir model was assess.

The Langmuir adsorption model assumes monolayer adsorption (the adsorbed layer is one molecule in thickness), with adsorption can only occur at a finite (fixed) number of definite localized sites, that are identical and equivalent, with no lateral interaction and strict hindrance between the adsorbed molecules, even on adjacent sites. In its derivation, Langmuir isotherm refers to homogeneous adsorption, which each molecule possess constant enthalpies and sorption activation energy (all sites possess equal affinity for the adsorbate), with no transmigration of the adsorbate in the plane of the surface.

Moreover, Langmuir theory stipulates a rapid decrease of the intermolecular attractive forces to the rise of distance [24].

The equation proposed by Langmuir was universally applicable to chemisorption with some restrictions involving physical adsorption where it is applicable adsorption on solid surface with one type of adsorption active center.

The Langmuir equation is given by:

$$
\frac{\mathrm{C}_{\mathrm{e}}}{\mathrm{q}_{\mathrm{e}}}=\frac{1}{\mathrm{Q}_{\mathrm{o}} \mathrm{b}}+\frac{\mathrm{C}_{\mathrm{e}}}{\mathrm{Q}_{\mathrm{o}}}
$$

where ' $\mathrm{C}_{\mathrm{e}}$ ' is the equilibrium concentration and ' $\mathrm{q}_{\mathrm{e}}$ ' is the amount of adsorbate adsorbed per gram of adsorbent at equilibrium ( $\mathrm{mg} / \mathrm{g})$; ' $\mathrm{Q}_{0}$ ' and ' $\mathrm{b}$ ' are Langmuir constants related to the sorption capacity and intensity respectively.

The notations qe and $\mathrm{Ce}$ are the concentration of adsorbate in solid phase at equilibrium $(\mathrm{mg} / \mathrm{g})$ and the concentration of adsorbate in liquid phase at equilibrium $(\mathrm{mg} / \mathrm{L})$ respectively. A linear plot was obtained when $C \mathrm{e} / q \mathrm{e}$ was plotted against $C \mathrm{e}$ over the entire concentration range evaluated.

The straight line indicates that the adsorption complies with the Langmuir mode as shown on Fig. 5. 


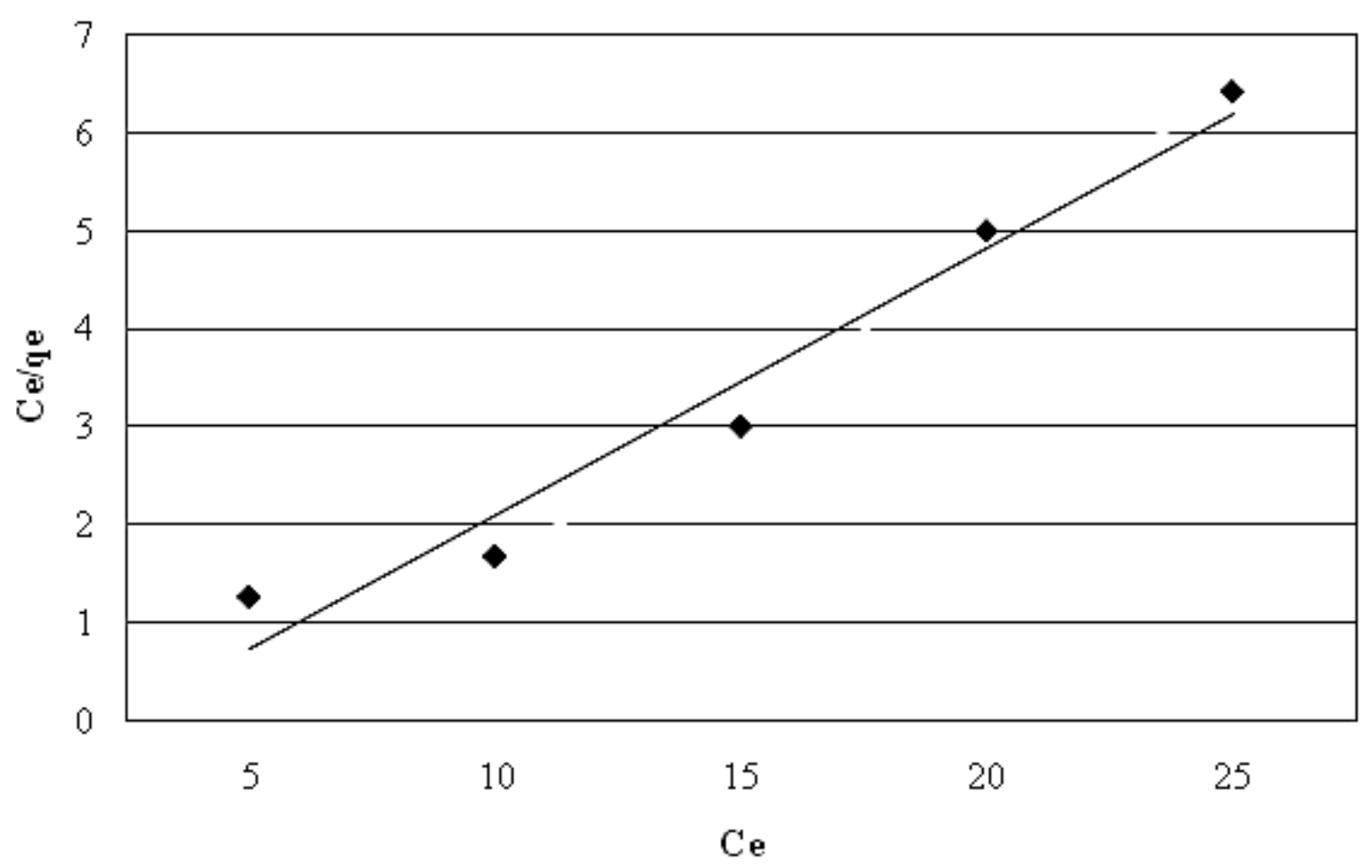

Fig. 5. Langmuir adsorption isotherm for rice husk.
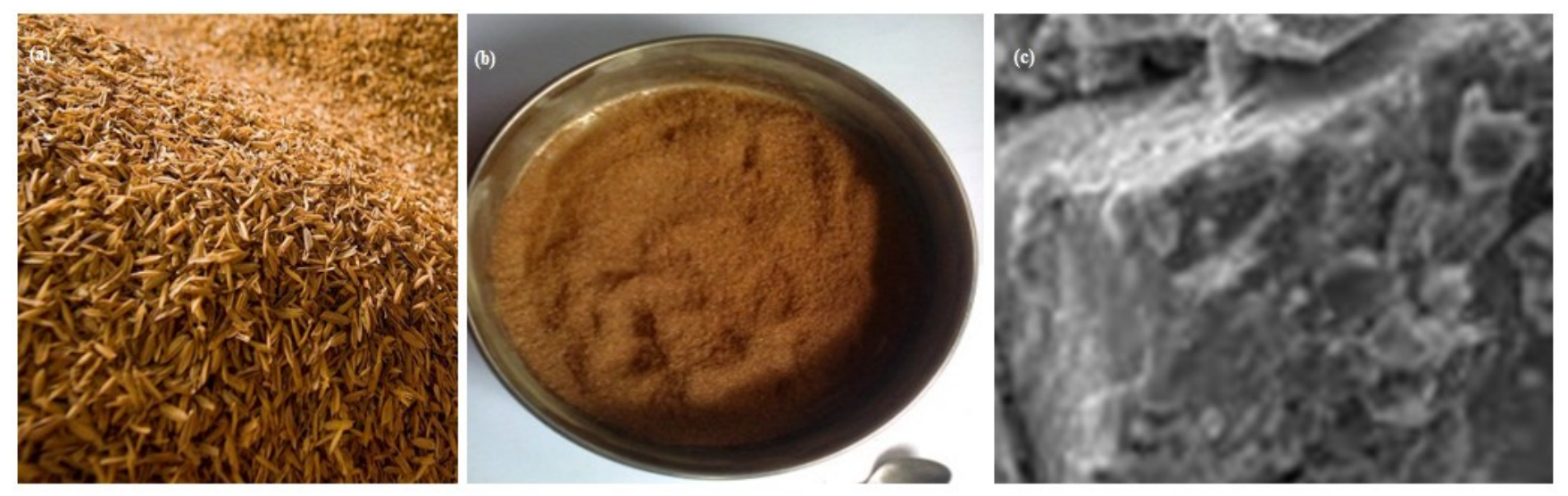

Fig. 6. Rice husk (a) raw (b) grinded (c) surface of rice husk.

In Fig. 6(a) the rice husk which is collected from rice industry found brownish yellow in color. That can be dried at $60^{\circ} \mathrm{C}$ in oven for around $12 \mathrm{~h}$. Dry rice husk was grinded with the help of grinder and make it fine with the help of mesh according to requirement, which is shown in Fig. 6(b).

Before adsorption the rice husk was scanning with electron micrographic equipment which is shown in Fig. 6(c). It was found rice husk greater surface are which is responsible for high efficiency. 


\section{CONCLUSION}

It is concluding that selection and identification of an appropriate low-cost adsorbent is one of the key issues to achieve the maximum removal/adsorption of specific type of pollutant depending upon the adsorbent-adsorbate characteristics. By comparatively study between clay, algae, moringa oleifera and rice husk for adsorption of phenol rice husk shown $97 \%$ adsorption at $150 \mathrm{~min}$ of contact time. Other adsorbent moringa oleifera $95 \%$, clay 93 $\%$ and algae $91 \%$ adsorption shows at same condition. Rice husk are available easy and economical effectiveness for the reduction of phenol from water. The disposal of rice husk after uses was ecofriendly for soil.

\section{Reference}

[1] J. M. Clark, S. H. Bottrell, C. D. Evans, D. T. Monteith, R. Barlett, R. Rose, R. J. Newton, P. J. Chapman, (2010). Sci. Tot. Env. 408 (2010) 2768-2775.

[2] P. Dawe, J. Env. Engg. Sci. 5 (2006) 59-73.

[3] A. H. Havelaar, A. E. M. De Hollander, P. F. M. Teunis, E. G. Evers, H. J. Van Kranen, J. F. M. Versteegh, J. E. M. Van Koten, W. Slob, Env. Heal. Pers. 108(4) (2000) 315-321.

[4] J. Sohn, G. Amy, Y. Yoon, J AWWA 99(6) (2007) 145-153.

[5] P. E. Ndimele, A. A. Jimoh, Res. J. Environ. Sci. 5(5) (2011) 424-433.

[6] H. Sarma, J. Environ. Sci. Technol. 4 (2011) 118-138.

[7] K. A. Onysko, C. W. Robinson, H. M. Budman, The Can. J Chem. Engg. 80 (2002) 239-252.

[8] K. Bandhyopadhyay, D. Das, P. Bhattacharyya, B. R. Maiti, Biochem. Engg. J 8 (2001) 179-186.

[9] W. Sokol, Biochem. Engg. J. 15 (2003) 1-10.

[10] A. Kumar, S. Kumar, S. Kumar, Biochem. Engg. J 22 (2004) 151-159.

[11] W. Sokol, W. Korpal, Biochem. Engg. J. 20 (2004) 49-56.

[12] C. S. A. Sa, R. A. R. Boaventura, Biochem. Engg. J. 9 (2001) 211-219.

[13] A. V. Vinod, G. V. Reddy, Indian Chem. Engr., Section A 45(1) (2003) 20-27.

[14] A. A. M. G. Monteiro, R. A. R. Boaventura, A. E. Rodrigues, Biochem. Engg. J. 6 (2000) 45-49.

[15] B. C. Meikap, G. K. Roy, In. J Env. Pro. 15(1) (1995) 44-49.

[16] P. Pengthamkeerati, T. Satapanajaru, O. Singchan, J. Hazard. Mater. 53(3) 2008) 1149-1156.

[17] B. Emrah, M. O. Zacar, I. A. Sengil, Micropor. Mesopor. Mat. 115 (2008) 234-246.

[18] A. H. Mahvi, A. Maleki, A. Eslami, Am. J. Appl. Sci. 1 (2004) 321-326.

[19] M. Akhtar, M. I. Bhanger, S. Iqbal, S. M. Hasany, J. Hazard. Mater. 128 (2006) 44-52. 
[20] K. Srinivasan, N. Balasubaramanian, T. V. Ramakhrisna, Indian J. Environ. Health. 30 (1988) 376-387.

[21] N. Kannan, M. M. Sundaram, Dyes Pig. 51 (2001) 25-40.

[22] P. K. Malik, Dyes Pig. 56 (2003) 239-249.

[23] K. Mohanty J. T. Naidu B. C. Meikap M. N. Biswas, Ind. Eng. Chem. Res. 45 (2006) 5165-5171.

[24] M. Ahmaruzzaman, D. K. Sharma, J. Colloid Interface Sci. 287 (2005) 14-24.

[25] Yasabie Abatneh, Omprakash Sahu, International Letters of Natural Sciences 3 (2014) 44-55.

[26] S. Yimer, O. P. Sahu, International Letters of Natural Sciences 4 (2014) 1-14.

[27] R. Desai, O. P. Sahu, International Letters of Natural Sciences 4 (2014) 15-26.

[28] W. Anteneh, O. P. Sahu, International Letters of Natural Sciences 4 (2014) 27-35.

[30] Sajid Qurashi, Omprakash Sahu, International Letters of Natural Sciences 5 (2014) 35-44.

[31] Omprakash Sahu, International Letters of Natural Sciences 7 (2014) 35-43.

[32] Omprakash Sahu, International Letters of Natural Sciences 8(1) (2014) 1-8. 